\title{
The power of emotional valence-from cognitive to affective processes in reading
}

\author{
Ulrike Altmann ${ }^{1,2 *}$, Isabel C. Bohrn ${ }^{1,2}$, Oliver Lubrich ${ }^{2,3}$, Winfried Menninghaus ${ }^{2,4}$ and \\ Arthur M. Jacobs ${ }^{1,2,5}$
}

1 Department of Education and Psychology, Freie Universität Berlin, Berlin, Germany

2 Languages of Emotion, Freie Universität Berlin, Berlin, Germany

${ }^{3}$ German and Comparative Literature, Universität Bern, Switzerland

${ }^{4}$ Department of Philosophy and Humanities, Freie Universität Berlin, Berlin, Germany

${ }^{5}$ Dahlem Institute for Neuroimaging of Emotion, Freie Universität Berlin, Berlin, Germany

\section{Edited by:}

John J. Foxe, Albert Einstein College of Medicine, USA

Reviewed by:

Eveline De Bruin, Unilever R\&D

Vlaardingen, Netherlands

Ted Altschuler, Albert Einstein

College of Medicine, USA

\section{${ }^{*}$ Correspondence:}

Ulrike Altmann, Department of

Education and Psychology, Freie

Universität Berlin, Habelschwerdter

Allee 45, Berlin 14195, Germany.

e-mail: u.altmann@fu-berlin.de
The comprehension of stories requires the reader to imagine the cognitive and affective states of the characters. The content of many stories is unpleasant, as they often deal with conflict, disturbance or crisis. Nevertheless, unpleasant stories can be liked and enjoyed. In this fMRI study, we used a parametric approach to examine (1) the capacity of increasing negative valence of story contents to activate the mentalizing network (cognitive and affective theory of mind, ToM), and (2) the neural substrate of liking negatively valenced narratives. A set of 80 short narratives was compiled, ranging from neutral to negative emotional valence. For each story mean rating values on valence and liking were obtained from a group of 32 participants in a prestudy, and later included as parametric regressors in the fMRI analysis. Another group of 24 participants passively read the narratives in a three Tesla MRI scanner. Results revealed a stronger engagement of affective ToM-related brain areas with increasingly negative story valence. Stories that were unpleasant, but simultaneously liked, engaged the medial prefrontal cortex (mPFC), which might reflect the moral exploration of the story content. Further analysis showed that the more the $\mathrm{mPFC}$ becomes engaged during the reading of negatively valenced stories, the more coactivation can be observed in other brain areas related to the neural processing of affective ToM and empathy.

Keywords: emotion, empathy, fMRI, liking, literature, reading, theory of mind

\section{INTRODUCTION}

Humans are storytellers. They share daily experiences, tell each other anecdotes, and exchange gossip (Baumeister et al., 2004; Dunbar, 2004). Besides producing and performing live narratives (McAdams Dan, 2001; Habermas and de Silveira, 2008), individuals also extensively consume stories: we read them in newspapers and magazines, in biographies and novels, via videotext or on the internet (for the purpose of this paper, we will use the term story in a broad sense synonymous with narrative). Yet even when stories have a negative content, as they deal with conflicts or crises, individuals not only understand, but also appreciate or enjoy them. In a study by Berthoz et al. (2002), for example, stories with endings that were either embarrassing or violated social norms were rated as funnier compared to stories whose endings reaffirmed normative social behavior.

We have, however, only limited knowledge about the neural processing of the emotional valence of stories. On the one hand, research on the neural effects of valence focuses primarily on the level of single words (Kuchinke et al., 2005; see Citron, 2012 for a review) or sentences (Willems et al., 2010; Kuchinke et al., 2011). On the other hand, there is extensive literature on the cognitive and emotional neural processing underlying theory of mind (ToM) stories (Abu-Akel and Shamay-Tsoory, 2011; Brink et al., 2011; Schnell et al., 2011; Walter, 2012). In these studies, individuals are often asked to make explicit cognitive and affective attributions to auditory or visually presented stories, and the material is primarily selected for its capacity to invoke mental state attributions. What has not been investigated so far is the question to what extent the emotional valence of such stories might contribute to ToM related neural processes. Usually, no data concerning the valence of ToM stories were included in the analysis or reported as a selection criterion (but see Berthoz et al., 2002; Brink et al., 2011). In the current study, we therefore took a reversed approach and investigated the contribution of emotionally valenced story contents to ToM-related processing in a passive reading task. In particular, we were interested in whether increasing negative story valence would engage not only more brain regions related to affective processing, but also invite a stronger engagement of ToM-related regions. Story comprehension seems to be closely linked to ToM, as it presupposes the understanding of actions and intentions of real or invented protagonists (Ferstl et al., 2008).

In a recent meta-analysis, Mar (2011) reported a profound overlap between text-based ToM studies and non-text-based ToM 
studies that used cartoons, pictures, animations or games as stimuli. Common activations comprised the dorsomedial prefrontal cortex (dmPFC), bilateral posterior superior temporal sulcus (pSTS), right temproparietal junction (TPJ), left inferior frontal gyrus (IFG), bilateral medial temporal gyrus (MTG), and anterior STS. Moreover, the analysis revealed large overlaps between the ToM network and results from studies that primarily investigated comprehension of texts with a narrative structure rather than ToM.

The literature distinguishes two components of ToM: cognitive ToM and affective ToM (see Walter, 2012 for a recent review). Cognitive ToM refers to mental state attribution in general (goals, intentions and desires of others) and engages a network comprising the dmPFC, STS, and TPJ, as reflected in the meta-study by Mar (2011). Affective ToM can be used almost synonymously with cognitive empathy and relates to the capacity to understand another's affective state. Although the actual experience of a corresponding affective state is explicitly not assumed within the framework of this concept, recent data suggest an interplay of cognitive and affective processes (Schnell et al., 2011).

The first aim of the current study was to investigate the interplay of negative story content and ToM. We used a set of short narrative texts that were either neutral or negative in valence. The neutral stories deal with everyday events and actions. They meet the definition of prototypical third-person narratives as they "have a telic structure including an agent, a goal and a causal sequence connecting the agent's various actions with the achievement or nonachievement of the goal." (Hogan, 2003, p. 205). According to Bruner (1986, p. 35), good "storytelling, inevitably, is about compelling human plights that are "accessible" to readers." (Bruner, 1986, p. 35). "Access" to a story presupposes the comprehension of actions, intentions and goals of its protagonists, and should thus be closely linked with ToM processes (Mason and Just, 2009; Mar, 2011). We therefore assume that, compared to their neutral counterparts, the negative stories we used were more effective in their potential to engage ToM, as their negative valence is related to the above mentioned "plights".

For the understanding of affective processes in reading, the consideration of valence might be one aspect to consider. The issue of liking could be another one. Highly interesting artwork can be disturbing and unpleasant (Turner and Silvia, 2006), and it has been known since Aristotle's work on tragedy that narrative contents do not have to be pleasurable in the sense of positive valence in order to be liked. The second aim of the current study was to investigate the neural substrate of liking negatively valenced narratives. This at first glance paradoxical tendency to like and enjoy unpleasant contents has been investigated in media psychology regarding different narrative contexts, including tragic television news and crime drama (Zillmann et al., 1998; Raney, 2002; Raney and Bryant, 2002). The enjoyment of unpleasant stories is not limited to a positive ending; in fact, a film without happy-end can also be enjoyed (Schramm and Wirth, 2010). How can liking unpleasant stories be explained? Disposition-based theories (Zillmann, 1994) postulate the involvement of two key factors: empathy with the character and moral evaluation. Accordingly, the enjoyment of unpleasant stories depends on the affective disposition and empathic reactions towards the characters as well as on moral judgments of the outcomes the characters were confronted with (deserved/undeserved). Correspondingly, increased sad film enjoyment was reported for viewers with high empathy (de Wied et al., 1994). In a study on crime drama, Raney (2002) found that (a) the enjoyment of unpleasant contents was predicted by moral judgments and that (b) moral judgments were predicted by empathy. Parkinson and colleagues (2011) investigated the neural processing during moral judgments of stories containing harm, dishonesty, or disgust. The $\mathrm{dmPFC}$ was the only region that all scenarios had in common and that therefore might represents a general underlying evaluative processing. Together, these studies led us to the following assumptions: (1) If moral judgment is associated with the enjoyment of unpleasant stories, as reported for crime drama by Raney (2002), the dmPFC might be especially involved when negatively valenced (unpleasant) narratives are simultaneously liked. (2) If moral judgments of narratives are related to empathy, coactivation of empathy-related brain regions and $\mathrm{dmPFC}$ can be expected.

Growing evidence suggests that reading (especially reading fiction) has the capacity to modify personality traits (Djikic et al., 2009) and is associated with better performance on scales of empathy and social abilities (Mar et al., 2006). Therefore, further insight in the affective processes in reading can help to inform us about their contribution to ToM-related processes and their potential capacity to enhance ToM development.

To sum up, we hypothesized that (1) passive reading and comprehension of both stories with neutral and negative valence should engage the cognitive ToM network. (2) We further predicted that increasing negative story valence leads to (a) similar activation patterns of affect-related brain regions as found in previous studies on single-word and sentence level. Moreover, we expected to find (b) the affective ToM network to be involved, as the negative valence is intertwined with the plights and conflicts the protagonists are confronted with. Neutral narratives should invite less ToM processes because the protagonists (and along with them the reader) can follow their goals and intentions without major disturbances or complications. (3) We expected to find an interaction effect of negative valence and liking. In detail, reading stories that are considered negative but simultaneously liked should especially engage the $\mathrm{mPFC}$, reflecting the moral monitoring of the characters and the plights they have to deal with. (a) This region should show a functional coupling with brain areas related to ToM and affective processing.

\section{METHODS \\ MATERIAL}

We used 80 short narratives (mean number of words: 48 , range: 41-57), adopting half of them from the so called black stories, a narrative-based game $\left({ }^{\odot}\right.$ moses Verlag GmbH, 47906 Kempen, www.moses-verlag.de). The plot of these stories was negatively valenced (crimes, disasters, accidents), comparable to the content of daily news stories, but also of novels or crime stories. For the other half of the material, we created 40 additional narratives that had comparable content settings but were neutral in valence. In these stories, protagonists pursued their goals smoothly and were not confronted with plights. Negative and neutral narratives 
were matched on the number of protagonists, sentences, words, and syllables, as well as on word frequency and comprehensibility. We conducted a prestudy with 32 participants ( 16 female, 16 male) in order to make sure that content and style of the negative and the neutral narratives included only events that could possibly occur, and that they could be read under two contextlabel conditions ("real," "invented") which were used during the task in the MRI scanner. A second group of 32 participants (16 female, mean age $=24.6 ; \mathrm{SD}=4.3$ ) rated the material on valence ("How do you perceive the text?", scale from -3-"very negative" to 3-"very positive") and liking ("Do you like the text?," scale from 1-"I do not like it at all" to 7-"I like it very much"). The resulting mean rating values of each scale were then used in the fMRI experiment to modulate parametric regressors for the effect of valence and liking during reading (please refer to Table A7 in the appendix for further details on the prestudy).

\section{PARTICIPANTS}

Twenty-four healthy, right-handed volunteers (12 female, mean age $=26.5 ; \mathrm{SD}=6.7$ ) took part in the study. Participants were German native speakers and skilled readers (assessed with a screening test that provides normdata for adults; SLS — Salzburger Lesescreening, unpublished version). Only participants who did not know the game black stories and were naive to its content were included. All participants had normal or corrected-to-normal vision and gave informed written consent in accordance with the local research ethics committee.

\section{TASK}

A $2 \times 2$ repeated measures design was applied with one factor varying the story-type ("negative," "neutral") and a second factor varying the context in which a story was presented ("real," "invented"). 20 stories were shown in each factor combination (Figure 1). We pseudo-randomized the order of conditions as well as the presentation of the narratives across conditions, but all participants read exactly the same set of black stories and neutral narratives. During the fMRI experiment, a narrative was presented for $20 \mathrm{~s}$, displayed on five lines (shown $4 \mathrm{~s}$ each). Prior to the story, a context label (either "Real" or "Invented") was presented for $3 \mathrm{~s}$. Participants were requested to read the text silently and solve a verification task following each text. By means of a cue ("Real?" or "Invented?") participants were either asked, as an attention control task, whether the story they just read was real, or they were asked whether it was invented. Participants answered by pressing a button ("yes," "no"). The verification cues were presented in a pseudorandomized order to avoid motor preparation during the reading phase and to assure an equal assignment of question cues and required responses with regard to each condition. Additionally, participants completed the Interpersonal Reactivity Index (IRI; Davis, 1983; German version: Paulus, 2009), which provides a fourdimensional self-report estimate of empathy. In this study, we focus on the "empathic concern" subscale, which assesses the individual tendency to feel concern and compassion for other people, because empathic concern was found to be associated with increased interest in tragic television news (Hoffner et al., 2009) as well as with the perception of a liked partner being in pain (Singer et al., 2004). Empathic concern scores showed a mean of 13.09 and a standard deviation of 1.79 (corresponding mean of German population norms $=14.56, \mathrm{SD}=2.94$; norm data retrieved from Paulus, C., "Normtabellen des SPF," last modified November 21, 2011, http://bildungswissenschaften. uni-saarland.de/personal/paulus/empathy/Normen.pdf).

\section{IMRI DATA ACQUISITION}

Functional data were acquired on a Siemens Tim Trio $3 \mathrm{~T}$ MR imager at $3 \mathrm{~T}$ field strength. Four runs of 425 volumes were measured using a T2* weighted echo-planar sequence [slice thickness,

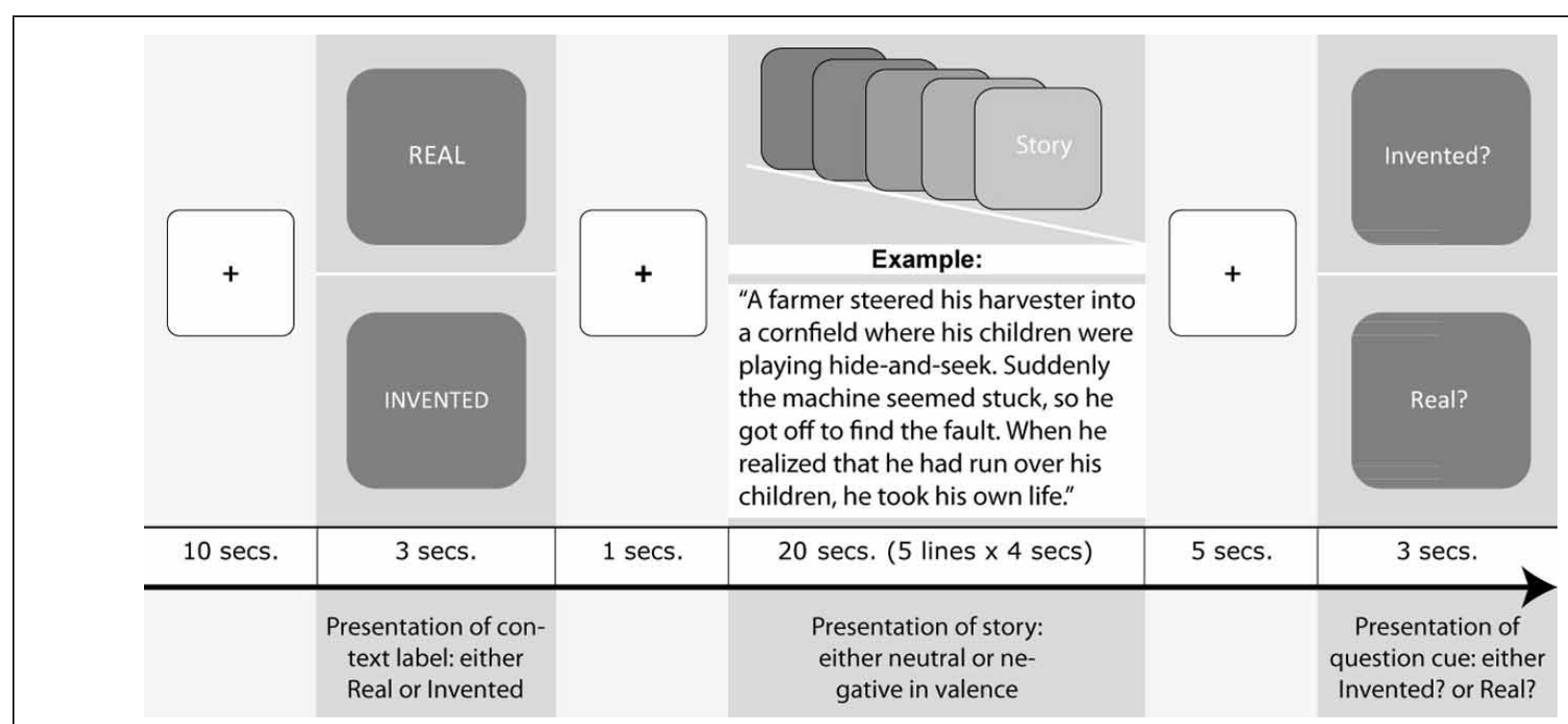

FIGURE 1 | Experimental design and stimuli. 
$3 \mathrm{~mm}$; no gap; 37 slices; repetition time (TR), $2 \mathrm{~s}$; echo time (TE), $30 \mathrm{~ms}$; flip angle, $90^{\circ}$; matrix, $64 \times 64$; field of view (FOV), $192 \mathrm{~mm}$; voxel-size $3.0 \times 3.0 \times 3.0 \mathrm{~mm}$ ], and individual highresolution T1-weighted anatomical data (MPRAGE-sequence) were acquired (176 slices; FOV, 256; TE, 2.52; TR, 1.9; matrix, $256 \times 256$; resolution $1.0 \times 1.0 \times 1.0 \mathrm{~mm}$; sagittal plane; slice thickness, $1 \mathrm{~mm})$.

\section{DATA ANALYSIS}

Analysis of fMRI data was conducted with Brain Voyager QX [2.0] (Brain Innovation, Maastricht, Netherlands; Goebel et al., 2006). Functional Data were corrected for head-motion and for different slice scan times using cubic spline interpolation. To remove low-frequency signal drifts, a high-pass filter was applied with a cutoff period three times the block length. Spatial smoothing was performed using a Gaussian filter of $8 \mathrm{~mm}$, full width at half maximum. The functional maps of each participant were then transformed into standard Talairach space (Talairach and Tournoux, 1988).

Whole-brain statistical analysis was performed according to the general linear model as implemented in Brain Voyager QX. On the first level, the model was generated with two blocked regressors for the reading of stories (negative, neutral) and two blocked regressors for the instruction and attention task periods. Three different models were constructed: (1) the first model included an additional parametric regressor containing the mean valence for each story/narrative, (2) the second model was added by a parametric regressor containing the mean liking values for each story/narrative (3) and in the third model we added the parametric interaction term of valence and liking (valence $\times$ liking). For each model, individual contrast images from the first level analysis were then applied to a second level random effects group analysis, in which we tested for the parametric effects of (1) reading negatively valenced stories (2) liking of texts, and (3) the corresponding interaction (valence $\times$ liking). All parametric contrasts were reported whole brain corrected $(p<0.05)$ using false discovery rate (FDR), and with an extend threshold of $k=20$ voxels for the resulting clusters.

In correspondence with our initial hypotheses, we identified the $\mathrm{mPFC}$ as involved in the interaction of negative valence $x$ liking and selected it as the seed region for further psychophysiological interaction (PPI) analysis (Friston et al., 1997) with a sphere of $10 \mathrm{~mm}$ around the peak voxel $(-9,41,16)$. PPI analysis provides a measure for task related functional connectivityit allows identifying brain regions that show a stronger coactivation during one task (reading negative stories) as compared to another (reading neutral stories). Particularly we were interested in whether valence-specific mPFC activation (i.e., reading negative stories) is "coupled" with emotion and ToM-related brain areas, especially the temporal poles (TP), the IFG, and the temporoparietal junction (TPJ). The PPI regressor was calculated as the element-by-element product of the mean corrected mPFC region of interest, and the task vector coding for the valence-specific effect of reading black stories compared to reading neutral narratives. To identify areas of the brain that showed increased activity while reading black stories when $\mathrm{MPFC}$ activity increased, individual PPI regressors where entered into a second level random effects analysis [reported whole brain corrected $(p<0.05)$ using FDR, $k=20$ voxels]. Finally, we repeated the analysis with individual scores on the empathic concern scale of the IRI as covariate to examine areas of the brain that showed a stronger coupling with mPFC depending on the individual tendency to feel concern for other people [cluster level corrected $(p<$ 0.05) using Monte Carlo simulations as implemented in Brain Voyager, initial voxel level threshold $p<0.001$ uncorrected].

\section{RESULTS}

\section{CONJUNCTION OF NEGATIVE AND NEUTRAL NARRATIVES}

Prior to the analysis that focused on emotional valence, we applied a conjunction analysis in order to assess the common effects of neutral and negative narratives (Table A1 and Figure 2A). This analysis revealed that neutral and negative narratives share extensive activation patterns including brain areas that are regularly reported for cognitive ToM, namely the dmPFC (BA 9), bilateral TP (TP: BA 38), and posterior superior temporal gyrus (pSTG: BA 22/39).

\section{PARAMETRIC EFFECTS}

First, we analyzed the parametric effect of negative valence (Table A2 and Figure 2B). This led to subcortical activations in the left striatum (caudate body), left mediodorsal thalamus, and left amygdala. Furthermore, the analyses revealed an extensive fronto-temporal network including the left mPFC (mPFC: BA 8/9), the bilateral IFG (IFG: BA 45/47), and the TP (TP: BA 38), the left fusiform/parahippocampal gyrus (BA 20/36), the bilateral middle temporal gyrus (MTG: BA 21) and STG (BA 22), as well as the bilateral posterior superior temporal gyrus extending to the temporal parietal junction (STG/TPJ: BA 39).

Second, we analyzed the parametric effect of liking (Table A3). Activations were found in the bilateral anterior STG/TP (BA 38), anterior MTG (BA 21), IFG (IFG: BA 45/47), lingual/fusiform gyrus (BA 18/19), and left posterior cingulate cortex (PCC: BA 30).

Third, we analyzed the parametric interaction effect of valence and liking (Table A4 and Figure 2C). Increasing negative valence combined with increasing values of liking was associated with activations in the bilateral $\mathrm{mPFC}(\mathrm{BA} 9,32)$, supramarginal gyrus/TPJ (BA 39/40), and left dorsolateral prefrontal cortx (DLPFC: BA 8).

\section{PPI ANALYSIS}

Next, we examined the results of the PPI analysis with the mPFC as the seed region, as this region revealed an interaction effect of valence $\times$ liking (Table A5 and Figure 3). Several regions showed a stronger coactivation with the $\mathrm{mPFC}$ during the reading of the negatively valenced stories as compared to the neutral narratives (negative $>$ neutral). Such coactivations could be observed bilaterally in the IGF extending into the insula (BA 45/47/13), the thalamus, the supramarginal gyrus (BA 40), and the vmPFC (BA 10) as well as in the left amygdala, the right dorsal striatum and the dorsal ACC (BA 32).

An additional PPI analysis was applied to take the individual tendency to feel concern for other people into account. It was tested which areas of the brain showed higher functional 

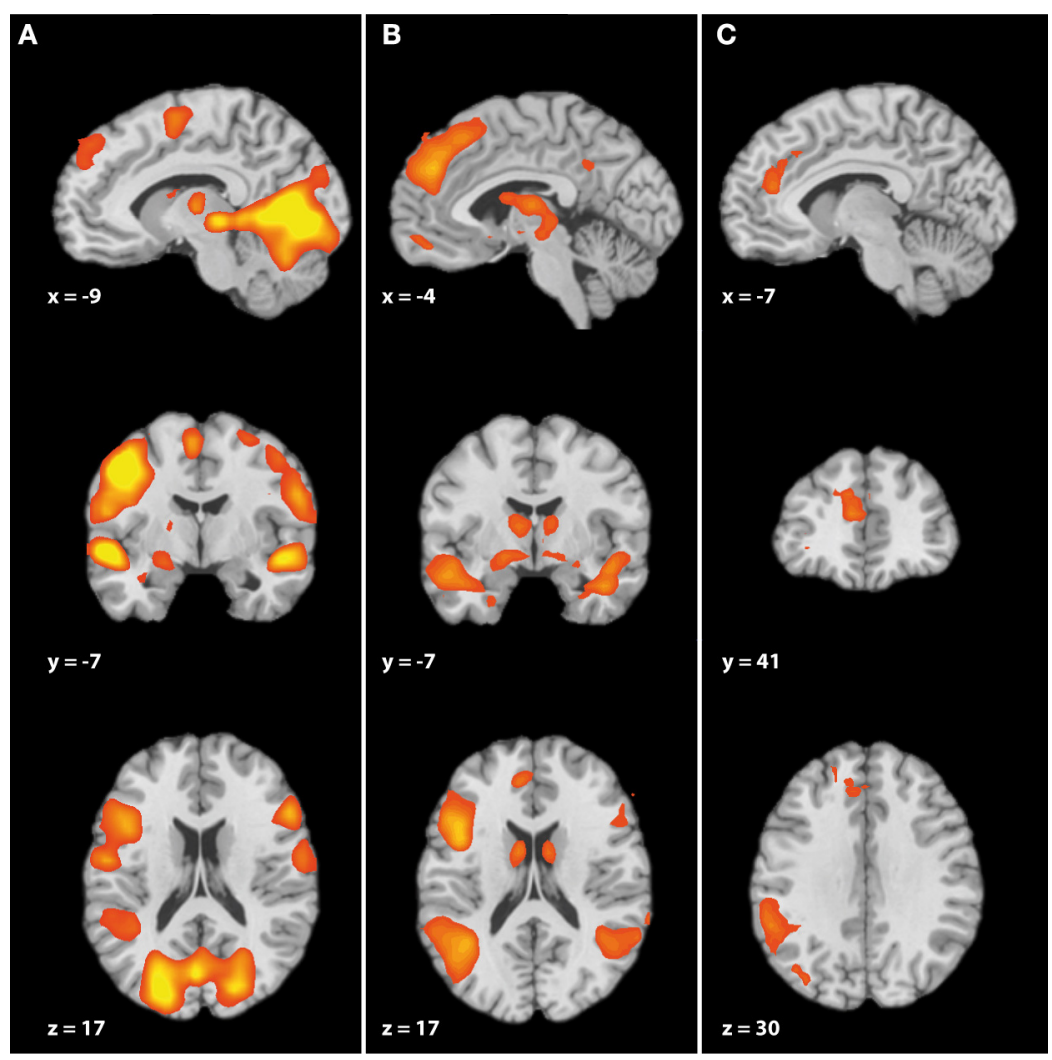

FIGURE 2 | (A) Brain activation for story reading - conjunction of negative stories and neutral stories (B) Parametric effect of increasing negative valence (C) Brain activation for increasing negative story valence combined with increasing story liking-Parametric interaction of valence $\times$ linking, whole brain corrected $(p<0.05)$ using FDR. connectivity with $\mathrm{mPFC}$ during reading negative stories, depending on self-report scores at the empathic concern scale. The bilateral anterior insula (BA 13) and the right posterior cingulate cortex (BA 31) (Table A5 and Figure 4) showed a stronger coupling with $\mathrm{mPFC}$ for individuals who reported a stronger tendency to feel concern for other people [cluster level corrected $(p<0.05)$, initial voxel level threshold $p<0.001$ uncorrected].

\section{DISCUSSION}

\section{THE INTERPLAY OF STORY VALENCE AND TOM}

This study aimed to investigate the hypothesis that narratives with negatively valenced content invite for an increased engagement of the affective mentalizing network (cognitive empathy). The conjunction analysis between neutral and negatively valenced narratives showed that they share the cognitive ToM network, including dmPFC, bilateral TP, and left pSTS.

As hypothesized, these regions became more engaged with increasing negative valence. The parametric analysis of valence revealed activations in the bilateral posterior STS/TPJ and the anterior subdivision of the mentalizing network, comprising dmPFC, TP, and aSTS/MTG. This network appears to be especially involved when mental state reasoning requires the interplay of cognitive and affective components (cognitive empathy; Preston and de Waal, 2002), e.g., for the inference of another person's affective state. In a recent study, Schnell and colleagues (Schnell et al., 2011) investigated cognitive empathy and found a simultaneous activation of the anterior mentalizing network and limbic structures, including the left amygdala, when affective as compared to non-affective visuospatial states had to be inferred. This network could also be observed when the participants made affective judgments about social contexts from their own point of view, without being explicitly asked to adopt a third-person perspective. This fits the requirements of the task used in the current experiment, as our participants were asked simply to read the short narratives.

In line with those previous findings our results suggest a close link between affective and cognitive components for mentalizing. Two key areas of cognitive ToM, the dmPFC and the TPJ, were also related to valence. Particularly, the dmPFC and the TPJ region seem to increase activation when updates of characterrelated information and the processing of intentions are needed (Saxe and Wexler, 2005; Mason and Just, 2009). In a study of Hooker and colleagues (Hooker et al., 2008), participants had to infer the emotional responses of characters in social scenes. In order to predict correctly whether an emotional response of a character might change or remain constant participants had to update their character-related information. In line with our results, the engagement of regions associated with mentalizing 


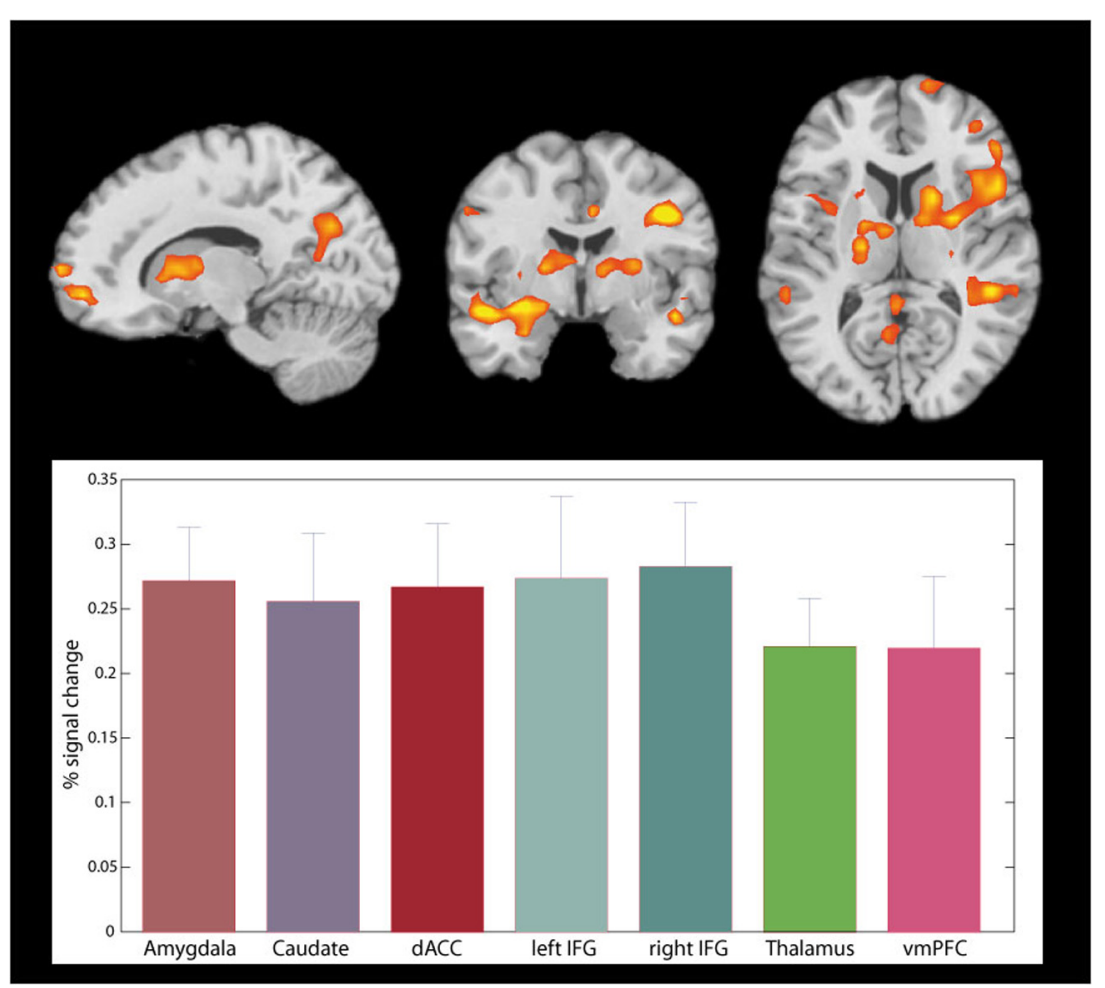

FIGURE 3 | Brain regions showing positive connectivity with mPFC while reading negative stories compared to reading neutral stories, whole brain corrected $(p<0.05)$ using FDR.

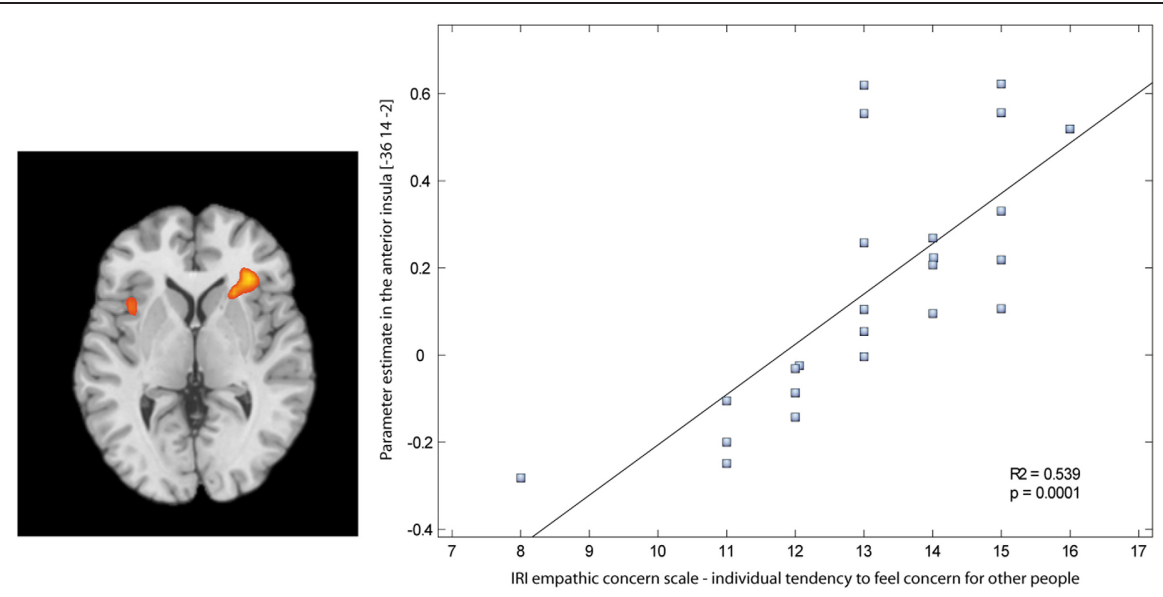

FIGURE 4 | Positive connectivity between $\mathrm{mPFC}$ and the anterior insula correlates with the individual tendency to feel concern for other people (Positive correlation between the empathic concern scale and
mPFC-connectivity while reading negative stories compared to reading neutral stories), cluster level corrected $(p<0.05)$, initial voxel level threshold $p<0.001$ uncorrected.
(STS/TPJ, mPFC, TP) and with emotion (IFG, thalamus) was higher when the emotions of a character were likely to change and unlikely to remain constant.

These observations are compatible with the negative stories in the current study: here, the intentions and emotions of the characters often changed as they were confronted with several "plights" (Bruner, 1986). In the neutral stories, on the other hand, the characters could act upon their goals without major disturbances. Apparently, the conflicts implicated in the negative stories evoke more attributions of goals and thoughts to the characters, as opposed to the neutral, everyday stories. Such attributions and inferences are essential for understanding the character and the story at large. And with increasingly negative emotional valence, reading stories also engaged 
the bilateral IFG and additional subcortical structures commonly involved in emotion processing, namely the bilateral dorsal striatum (caudate body), left mediodorsal thalamus, and left amygdala.

The thalamus appears to be involved in general emotion processing, independent of valence (Lane et al., 1997; Goldin et al., 2005) or social/nonsocial content (Britton et al., 2006) and has been shown to be involved when subjects empathize with a protagonist suffering a threat (emotional empathy) compared to empathizing with a protagonist in a neutral everyday (cognitive empathy) situation (Nummenmaa et al., 2008). Engagement of the amygdala has been reported for viewing pictures of negative emotion (Lane et al., 1997) and watching sad films (Goldin et al., 2005), but, similar to the thalamus, this structure is presumably more sensitive to the salience than to the valence of affective stimuli (Phan et al., 2004; Britton et al., 2006).

In correspondence with our results, a recent meta analysis (Mar, 2011) identified lefthemispheric amygdala activation to be associated with story-based ToM, whereas righthemispheric activation was found for nonstory-based ToM.

The IFG, which showed to be responsive to both emotional valence and liking in the present study, is considered a possible human analogue to the mirror neuron system (Rizzolatti and Craighero, 2004; Iacoboni, 2009). It was reported for the imitation and observation of emotion in pictures (Carr et al., 2003), imagery of emotional scripts (Sabatinelli et al., 2006), and might also play a role in affective mentalizing (Schnell et al., 2011). In correspondence with our results, Hynes et al. (2006) observed the orbital part of the bilateral IFG (BA 47) and the left IFG (BA 11) to be more strongly engaged in emotional perspective taking than in cognitive perspective taking in a story-based mentalizing task. Furthermore, potential mirror neuron activation in bilateral IFG and STS was found to correlate with empathy scores (Schulte-Rüther et al., 2007).

\section{LIKING OF UNPLEASANT STORY CONTENTS}

The parametric interaction analysis showed that when valence and liking come together, the activation peak of the mPFC moves inferiorly and closer to the anterior cingulate gyrus $(-9,41,16)$, compared to the activation peak resulting from the parametric valence effect alone $(-6,44,31)$. For reading negatively valenced narratives (as compared to neutral ones) this region showed a functional coupling not only with regions related to ToM, but also with regions known to be involved in affective empathy (amygdale, anterior insula, midcingulate cortex, and IFG; Walter, 2012). These results were supported by the additional result showing a stronger functional coupling between the mPFC seed region and bilateral anterior insula engagement when the magnitude of the participant's empathic concern is taken into account. Similar correlations between the anterior insula and self-reported empathy have been observed for empathy of social pain (Masten et al., 2011), and for the observation of other individuals receiving pain (Singer et al., 2004, 2006).

These results support our initial hypotheses derived from media psychology, which assumed that moral evaluations and empathic reactions to characters in stories influence liking of unpleasant story contents (Raney, 2002; Parkinson et al., 2011). Further studies will be needed to systematically investigate the potential role of moral reasoning and its relationship to empathy for affective and aesthetic processes in reading. Empathy and moral reasoning about characters provide two possible factors which influence enjoyment in reading. Others are very likely involved as well, for instance stylistic features (Miall and Kuiken, 1994; Jacobs, 2011) and provided details (see Green et al., 2004 for an overview). A major challenge for future research will be the implementation of paradigms that allow us to follow the temporal dynamics of reading, particularly of longer, wellcrafted stories. As Green and Brock (2000) showed, well-crafted, canonical stories were rated as more immersive. First steps in that direction have already been made (e.g., Wallentin et al., 2011).

\section{LIMITATIONS OF THE STUDY}

The values for valence and liking that were used for the parametric analysis of the fMRI study reflect mean data that were derived from a prestudy and as such treated as characteristics of the stories. The fact that we did not use individual subject ratings of the fMRI sample might limit the conclusions that can be drawn from the results.

We decided for an implicit reading task as it was one purpose of the study to assess the interplay of valence, liking and ToM during (as much as possible) natural reading of stories. Post scan data of individual subjects for valence and liking might have strengthened the results. On the other hand, the usage of pretest data allowed preventing subjects from fatigue effects, likely arising for rating the 80 stories again during an additional postscan session. Moreover, it has been shown that especially liking judgments can change with repeated exposure (Tan et al., 2006), which might have distorted our data. The standard deviations for liking judgments were comparable to those of valence (Table A7). Thus, it could be excluded that the evaluation of liking implies lower intersubject agreement than the evaluation of valence. Similar observations have been made for judging the attractiveness of faces (for an overview see Chatterjee et al., 2009) and for reading poems (Martindale and Dailey, 1995). Given these potential limitations, we consider a similar study using postscan rating data desirable as to further inform us about individual effects in the reader and to strengthen the present results.

\section{CONCLUSION}

To summarize, taking the emotional valence (from neutral to negative) of the content of stories into account reveals the full scale of ToM-related processing, ranging from cognitive and affective ToM to components of affective empathy through top-down processing during reading (Walter, 2012). Therefore, it seems worthwhile to include valence for the investigation of ToM and related processes either as a variable of interest or as control variable (e.g., between conditions of interest and control conditions). Given the extensive use of stories in our daily life, their capacity to provide simulations of the social world (Mar and Oatley, 2008), and to evoke even emotional reactions as complex as liking unpleasant contents, we should attempt to improve our understanding of the underlying 
mechanisms and of how these processes might relate to learning and development.

\section{ACKNOWLEDGMENTS}

This research was supported by the DFG-funded Cluster of Excellence "Languages of Emotion" and the Dahlem Institute for Neuroimaging of Emotion (D.I.N.E.), Freie Universität Berlin. We are grateful to Christine Knoop for helpful comments on earlier versions of the manuscript. We also thank Isabel Amberger, Moritz Matejka, Anja Wenzel, and Skadi Wilke for their help in subject recruitment and data acquisition.

\section{REFERENCES}

Abu-Akel, A., and Shamay-Tsoory, S. (2011). Neuropsychologia neuroanatomical and neurochemical bases of theory of mind. Neuropsychologia 49, 2971-2984.

Baumeister, R. F., Zhang, L., and Vohs, K. D. (2004). Gossip as cultural learning. Rev. Gen. Psychol. 8, 111-121.

Berthoz, S., Armony, J. L., Blair, R. J. R., and Dolan, R. J. (2002). An fMRI study of intentional and unintentional (embarrassing) violations of social norms. Brain 125, 1696-1708.

Brink, T., Urton, K., Held, D., Kirilina, E., Hofmann, M., Klann-Delius, G., Jacobs, A. M., and Kuchinke, L. (2011). The role of orbitofrontal cortex in processing empathy stories in 4-8 year-old children. Front. Psychol. 2:80. doi: 10.3389/fpsyg.2011.00080

Britton, J. C., Phan, K. L., Taylor, S. F., Welsh, R. C., Berridge, K. C., and Liberzon, I. (2006). Neural correlates of social and nonsocial emotions: an fMRI study. Neuroimage 31, 397-409.

Bruner, J. (1986). Actual Minds, Possible Worlds. Cambridge, MA: Harvard University Press.

Carr, L., Iacoboni, M., Dubeau, M.-C., Mazziotta, J. C., and Lenzi, G. L. (2003). Neural mechanisms of empathy in humans: a relay from neural systems for imitation to limbic areas. Proc. Natl. Acad. Sci. U.S.A. 100, 5497-5502.

Chatterjee, A., Thomas, A., Smith, S. E., and Aguirre, G. K. (2009). The neural response to facial attractiveness. Neuropsychology 23, 135-143.

Citron, F. M. M. (2012). Neural correlates of written emotion word processing: a review of recent electrophysiological and hemodynamic neuroimaging studies. Brain Lang. Advance online publication. doi: 10.1016/j.bandl.2011.12.007

Davis, M. H. (1983). Measuring individual differences in empathy: evidence for a multidimensional approach. J. Pers. Soc. Psychol. 44, 113-126.

de Wied, M., Zillmann, D., and Ordman, V. (1994). The role of empathic distress in the enjoyment of cinematic tragedy. Poetics 23, 91-106.

Djikic, M., Oatley, K., Zoeterman, S., and Peterson, J. (2009). On being moved by art: how reading fiction transforms the self. Creativity Res. J. 21, 24-29.

Dunbar, R. I. M. (2004). Gossip in evolutionary perspective. Rev. Gen. Psychol. 8, 100-110.

Ferstl, E. C., Neumann, J., Bogler, C., and von Cramon, D. Y. (2008). The extended language network: a metaanalysis of neuroimaging studies on text comprehension. Hum. Brain Mapp. 29, 581-593.

Friston, K. J., Buechel, C., Fink, G. R., Morris, J., Rolls, E., and Dolan, R. J. (1997). Psychophysiological and modulatory interactions in neuroimaging. Neuroimage 6 218-229.

Goebel, R., Esposito, F., and Formisano, E. (2006). Analysis of functional image analysis contest (FIAC) data with Brainvoyager QX: from singlesubject to cortically aligned group general linear model analysis and self-organizing group independent component analysis. Hum. Brain Mapp. 27, 392-401.

Goldin, P. R., Hutcherson, C. A. C., Ochsner, K. N., Glover, G. H., Gabrieli, J. D. E., and Gross, J. J. (2005). The neural bases of amusement and sadness: a comparison of block contrast and subjectspecific emotion intensity regression approaches. Neuroimage 27, 26-36.

Green, M. C., Brock, T. C., and Kaufman, G. F. (2004). Understanding media enjoyment: the role of transportation into narrative worlds. Commun. Theory 14, 311-327.

Green, M. C., and Brock, T. C. (2000). The role of transportation in the persuasiveness of public narratives. J. Pers. Soc. Psychol. 79, 701-721.

Habermas, T., and de Silveira, C. (2008). The development of global coherence in life narratives across adolescence: temporal, causal, and thematic aspects. Dev. Psychol. 44, 707-721.

Hoffner, C. A., Fujioka, Y., and Ye, J. (2009). Mass communication and society why we watch: factors affecting exposure to tragic television news. Communication 12 , 193-216.

Hogan, P. C. (2003). The Mind and Its Stories: Narrative Universals and Human Emotion. Cambridge, MA: Cambridge University Press.

Hooker, C. I., Verosky, S. C., Germine, L. T., Knight, R. T., and D'Esposito, M. (2008). Mentalizing about emotion and its relationship to empathy. Soc. Cogn. Affect. Neurosci. 3, 204-217.

Hynes, C. A., Baird, A. A., and Grafton, S. T. (2006). Differential role of the orbital frontal lobe in emotional versus cognitive perspectivetaking. Neuropsychologia 44, 374-383.

Iacoboni, M. (2009). Imitation, empathy, and mirror neurons. Annu. Rev. Psychol. 60, 653-670.

Jacobs, A. M. (2011). "Neurokognitive Poetik: Elemente eines Modells des literarischen Lesens (Neurocognitive poetics: elements of a model of literary reading)," in Gehirn und Gedicht: Wie wir unsere Wirklichkeiten konstruieren, eds R. Schrott and A. M. Jacobs (München, Germany: Carl Hanser Verlag), 492-524.

Kuchinke, L., Jacobs, A. M., Grubich, C., Võ, M. L.-H., Conrad, M., and Herrmann, M. (2005). Incidental effects of emotional valence in single word processing: an fMRI study. Neuroimage 28, 1022-1032.

Kuchinke, L., Schneider, D., Kotz S. A., and Jacobs, A. M. (2011) Spontaneous but not explicit processing of positive sentences impaired in Asperger's syndrome: pupillometric evidence. Neuropsychologia 49, 331-338.

Lane, R. D., Reiman, E. M., Bradley, M. M., Lang, P. J., Ahern, G. L., Davidson, R. J., and Schwartz, G. E. (1997). Neuroanatomical correlates of pleasant and unpleasant emotion. Neuropsychologia 35, 1437-1444.

Mar, R. A. (2011). The neural bases of social cognition and story comprehension. Annu. Rev. Psychol. 62, 103-134.

Mar, R. A., Oatley, K., Hirsh, J., Delapaz, J., and Peterson, J. (2006). Bookworms versus nerds: exposure to fiction versus non-fiction, divergent associations with social ability, and the simulation of fictional social worlds. J. Res. Pers. 40, 694-712.

Mar, R. A., and Oatley, K. (2008). The function of fiction is the abstraction and simulation of social experience. Psychol. Sci. 3, 173-192.

Martindale, C., and Dailey, A. (1995). I.A. Richards revisited: do people agree in their interpretations of literature? Poetics 23, 299-314.

Mason, R. A., and Just, M. A. (2009). The role of the theory-of-mind cortical network in the comprehension of narratives. Lang. Linguist. Compass 3, 157-174.

Masten, C. L., Morelli, S. A., and Eisenberger, N. I. (2011). Neuroimage an fMRI investigation of empathy for "social pain" and subsequent prosocial behavior. Neuroimage 55, 381-388.

McAdams Dan, P. (2001). The psychology of life stories. Rev. Gen. Psychol. 5, 100-122.

Miall, D. S., and Kuiken, D. (1994). Foregrounding, defamiliarization, and affect: response to literary stories. Poetics 22, 389-407.

Nummenmaa, L., Hirvonen, J., Parkkola, R., and Hietanen, J. K. (2008). Is emotional contagion special? An fMRI study on neural systems for affective and cognitive empathy. Neuroimage 43, 571-580.

Parkinson, C., Sinnott-Armstrong, W., Koralus, P. E., Mendelovici, A., McGeer, V., and Wheatley, T. (2011). Is morality unified? Evidence that distinct neural systems underlie moral judgments of harm, dishonesty, and disgust. J. Cogn. Neurosci. 23, 3162-3180.

Paulus, C. (2009). The Saarbruecken personality questionnaire on empathy: psychometric evaluation of the German version of the Interpersonal Reactivity Index. Available online at: http://www. uni-saarland.de/fak5/ezw/personal/ paulus/empathy/SPFArtikel.pdf

Phan, K. L., Wager, T. D., Taylor, S. F., and Liberzon, I. (2004). Functional neuroimaging studies of human emotions. CNS Spectr. 9, 258-266.

Preston, S. D., and de Waal, F. B. M. (2002). Empathy: its ultimate and 
proximate bases. Behav. Brain sci. $25,1-72$.

Raney, A. A. (2002). Moral judgment as a predictor of enjoyment of crime drama. Media Psychol. 4, 305-322.

Raney, B. A. A., and Bryant, J. (2002). Moral judgment and crime drama: an integrated theory of enjoyment. Communication 6, 402-415.

Rizzolatti, G., and Craighero, L. (2004). The mirror-neuron system. Annu. Rev. Neurosci. 27, 169-192.

Sabatinelli, D., Lang, P. J., Bradley, M. M., and Flaisch, T. (2006). The neural basis of narrative imagery: emotion and action. Prog. Brain Res. 156, 93-103.

Saxe, R., and Wexler, A. (2005). Making sense of another mind: the role of the right temporo-parietal junction. Neuropsychologia 43, 1391-1399.

Schnell, K., Bluschke, S., Konradt, B., and Walter, H. (2011). Functional relations of empathy and mentalizing: an fMRI study on the neural basis of cognitive empathy. Neuroimage 54, 1743-1754.

Schramm, H., and Wirth, W. (2010). Exploring the paradox of sad-film enjoyment: the role of multiple appraisals and meta-appraisals. Poetics 38, 319-335.

Schulte-Rüther, M., Markowitsch, H. J., Fink, G. R., and Piefke, M. (2007). Mirror neuron and theory of mind mechanisms involved in face-toface interactions: a functional magnetic resonance imaging approach to empathy. J. Cogn. Neurosci. 19, 1354-1372.

Singer, T., Seymour, B., O’Doherty, J. P., Stephan, K. E., Dolan, R. J., and Frith, C. D. (2006). Empathic neural responses are modulated by the perceived fairness of others. Nature 439, 466-469.

Singer, T., Seymour, B., O’Doherty, J., Kaube, H., Dolan, R. J., and Frith, C. D. (2004). Empathy for pain involves the affective but not sensory components of pain. Science 303, 1157-1162.

Talairach, J., and Tournoux, P. (1988). Co-Planar Stereotaxic Atlas of the Human Brain. New York, NY: Thieme.

Tan, S.-L., Spackman, M. P., and Peaslee, C. L. (2006). The effects of repeated exposure on liking and judgments of musical unity of intact and patchwork compositions. Music Percept. 23, 407-421.

Turner, S. A, and Silvia, P. J. (2006). Must interesting things be pleasant? A test of competing appraisal structures. Emotion 6, 670-674.

Wallentin, M., HØjlund, A., Vuust, P., Dohn, A., Roepstorff, A., and Ellegaard, T. (2011). Amygdala and heart rate variability responses from listening to emotionally intense parts of a story. Neuroimage 58, 963-973.

Walter, H. (2012). Social cognitive neuroscience of empathy: concepts, circuits, and genes. Emot. Rev. 4, 9-17.

Willems, R. M., Clevis, K., and Hagoort, P. (2010). Add a picture for suspense: neural correlates of the interaction between language and visual information in the perception of fear. Soc. Cogn. Affect. Neurosci. 6, 404-416.

Zillmann, D. (1994). Mechanisms of emotional involvement with drama. Poetics 23, 33-51.

Zillmann, D., Taylor, K., and Lewis, K. (1998). News as nonfiction theater: how dispositions toward the public cast of characters affect reactions. J. Broadcast. Electron. Media 42, 153-169.

Conflict of Interest Statement: The authors declare that the research was conducted in the absence of any commercial or financial relationships that could be construed as a potential conflict of interest.

Received: 12 March 2012; accepted: 09 June 2012; published online: 28 June 2012.

Citation: Altmann U, Bohrn IC Lubrich O, Menninghaus $W$ and Jacobs AM (2012) The power of emotional valence-from cognitive to affective processes in reading. Front. Hum. Neurosci. 6:192. doi: 10.3389/fnhum.2012.00192 Copyright (c) 2012 Altmann, Bohrn, Lubrich, Menninghaus and Jacobs. This is an open-access article distributed under the terms of the Creative Commons Attribution Non Commercial License, which permits non-commercial use, distribution, and reproduction in other forums, provided the original authors and source are credited. 


\section{APPENDIX}

Table A1 | Brain activation for story reading (negative stories AND neutral stories).

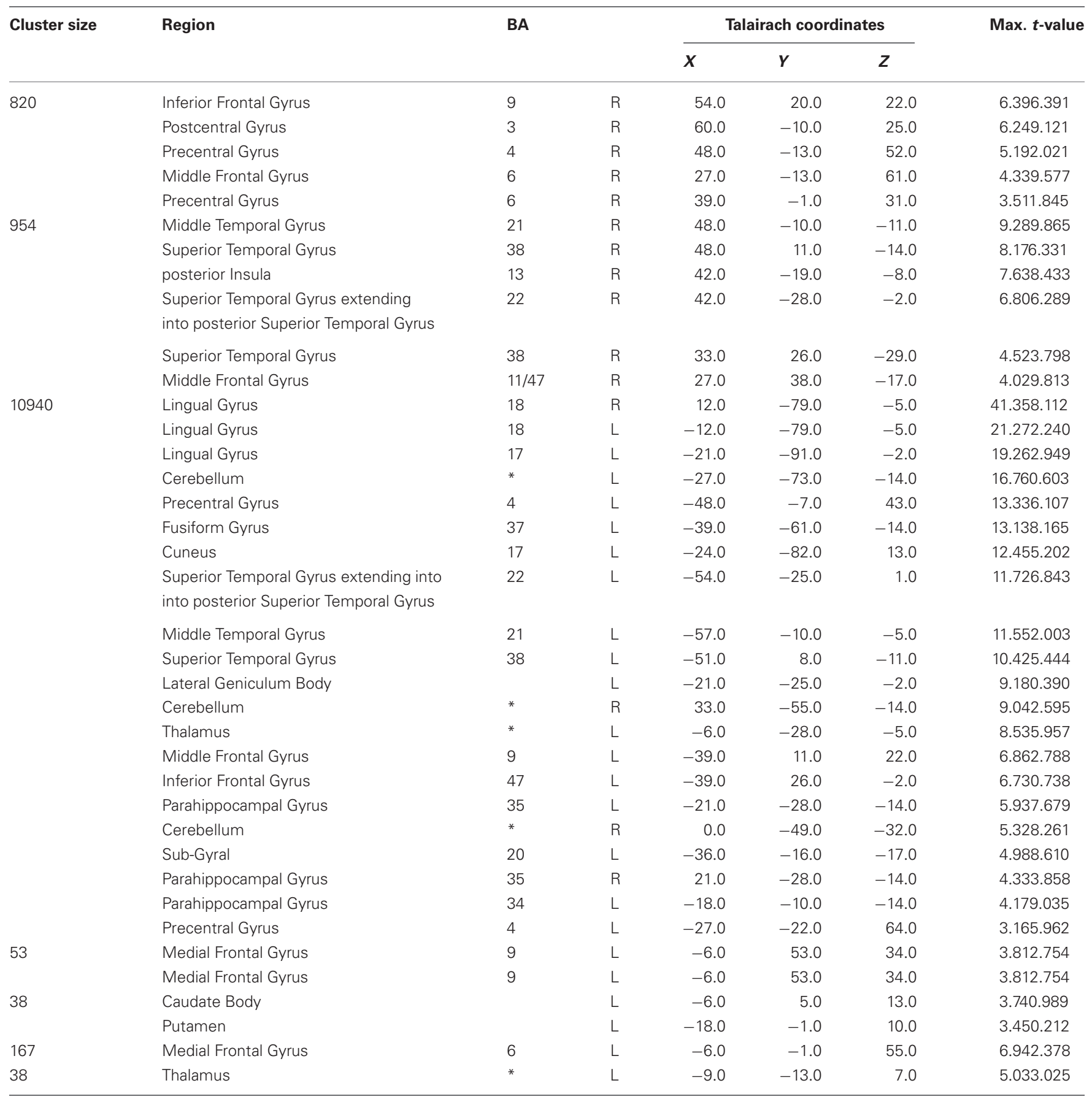


Table A2 | Brain activation for increasing negative story valence.

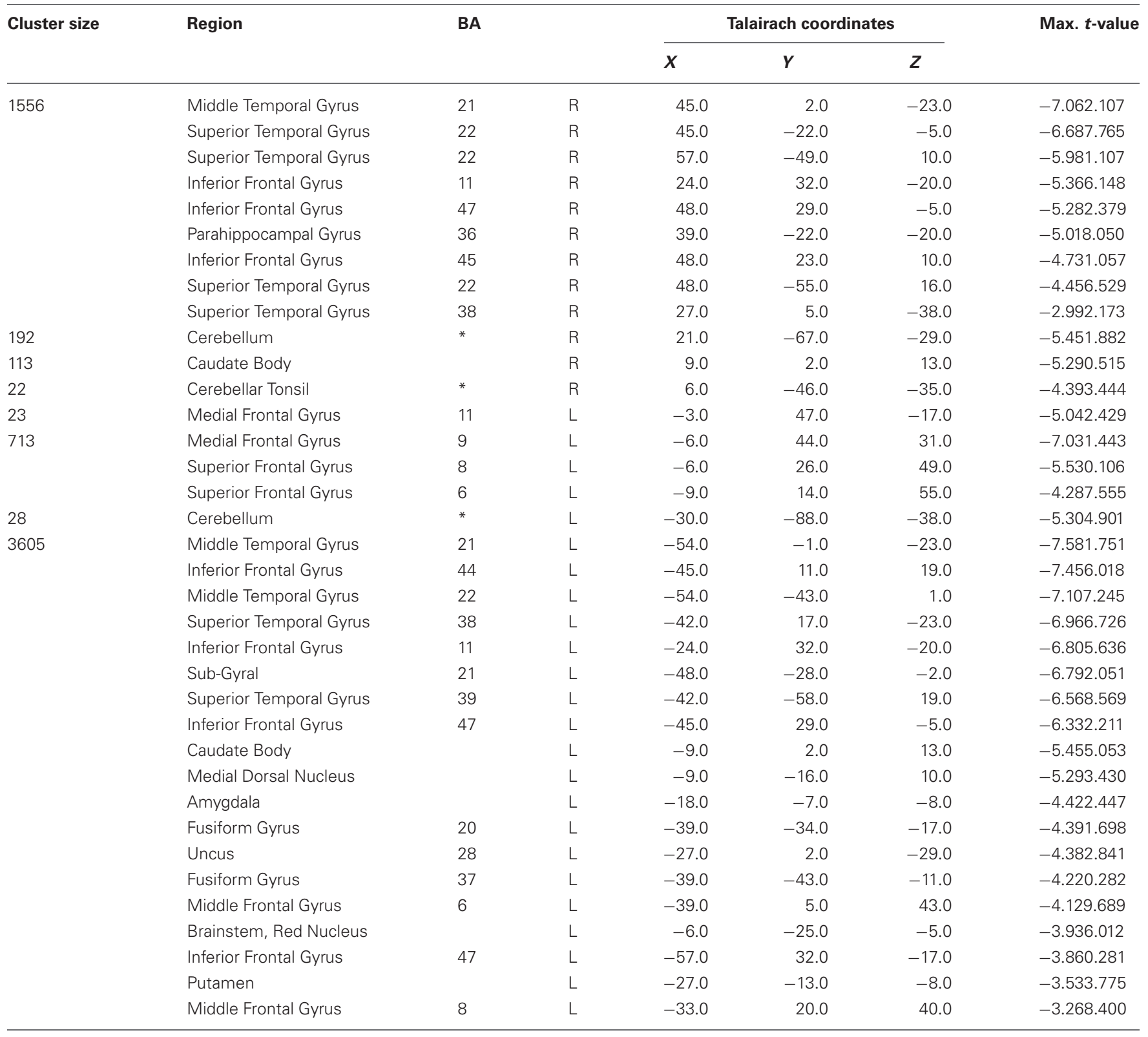


Table A3 | Brain activation for increasing story liking.

\begin{tabular}{|c|c|c|c|c|c|c|c|}
\hline Cluster size & Region & BA & & \multicolumn{3}{|c|}{ Talairach coordinates } & Max. $t$-value \\
\hline 103 & Inferior Frontal Gyrus & 45 & $\mathrm{R}$ & 54.0 & 20.0 & 10.0 & 4.666 .930 \\
\hline \multirow[t]{3}{*}{518} & Superior Temporal Gyrus & 38 & $\mathrm{R}$ & 42.0 & 14.0 & -20.0 & 5.721 .092 \\
\hline & Superior Temporal Gyrus & 38 & $\mathrm{R}$ & 54.0 & 20.0 & -26.0 & 5.406 .403 \\
\hline & Middle Temporal Gyrus & 21 & $\mathrm{R}$ & 57.0 & -1.0 & -14.0 & 5.036 .968 \\
\hline 30 & Precuneus & 31 & $\mathrm{R}$ & 24.0 & -73.0 & 22.0 & 4.332 .990 \\
\hline 25 & Medial Frontal Gyrus & 6 & $L$ & -6.0 & 2.0 & 61.0 & 4.623 .124 \\
\hline \multirow[t]{2}{*}{52} & Parahippocampal Gyrus & 28 & $\mathrm{~L}$ & -21.0 & -25.0 & -8.0 & 3.635 .541 \\
\hline & Cerebellum & * & $\mathrm{L}$ & -3.0 & -31.0 & -5.0 & 3.600 .545 \\
\hline \multirow[t]{18}{*}{3341} & Middle Temporal Gyrus & 22 & $\mathrm{~L}$ & -54.0 & -43.0 & 4.0 & 5.587 .103 \\
\hline & Cerebellum & * & $\mathrm{R}$ & 21.0 & -73.0 & -23.0 & 4.993 .320 \\
\hline & Middle Occipital Gyrus & 18 & $\mathrm{R}$ & 30.0 & -79.0 & -5.0 & 4.934 .392 \\
\hline & Cuneus & 19 & $\mathrm{~L}$ & -21.0 & -88.0 & 28.0 & 4.894 .963 \\
\hline & Inferior Frontal Gyrus & 45 & $\mathrm{~L}$ & -57.0 & 14.0 & 19.0 & 4.853 .875 \\
\hline & Lingual Gyrus & 17 & $\mathrm{R}$ & 12.0 & -88.0 & -2.0 & 4.847 .248 \\
\hline & Cuneus & 18 & $\mathrm{~L}$ & -18.0 & -94.0 & 13.0 & 4.788 .170 \\
\hline & Middle Occipital Gyrus & 18 & $\mathrm{R}$ & 24.0 & -94.0 & 10.0 & 4.667 .599 \\
\hline & Cerebellum & $*$ & $\mathrm{~L}$ & -33.0 & -61.0 & -8.0 & 4.616 .873 \\
\hline & Middle Occipital Gyrus & 19 & $\mathrm{~L}$ & -27.0 & -88.0 & 10.0 & 4.599 .266 \\
\hline & Inferior Occipital Gyrus & 18 & $\mathrm{R}$ & 30.0 & -94.0 & -5.0 & 4.459 .953 \\
\hline & Lingual Gyrus & 18 & $\mathrm{~L}$ & -18.0 & -55.0 & 4.0 & 3.980 .167 \\
\hline & Cuneus & 17 & $\mathrm{~L}$ & -9.0 & -76.0 & 10.0 & 3.888 .908 \\
\hline & Cerebellum & $*$ & $\mathrm{R}$ & 33.0 & -58.0 & -11.0 & 3.844 .507 \\
\hline & Inferior Occipital Gyrus & 18 & $\mathrm{~L}$ & -42.0 & -88.0 & -14.0 & 3.833 .167 \\
\hline & Inferior Frontal Gyrus & 11 & $\mathrm{~L}$ & -27.0 & 29.0 & -23.0 & 3.559 .359 \\
\hline & Cerebellum & $*$ & $\mathrm{~L}$ & -27.0 & -37.0 & -17.0 & \\
\hline & Parahippocampal Gyrus & 30 & $\mathrm{R}$ & 15.0 & -43.0 & 1.0 & 3.483 .598 \\
\hline
\end{tabular}


Table A4 | Brain activation for increasing negative story valence combined with increasing story liking (valence $\mathrm{x}$ linking).

\begin{tabular}{|c|c|c|c|c|c|c|c|}
\hline Cluster size & Region & BA & & \multicolumn{3}{|c|}{ Talairach coordinates } & Max. $t$-value \\
\hline \multirow[t]{2}{*}{266} & Supramarginal Gyrus & 40 & $L$ & -57.0 & -46.0 & 31.0 & -5.475 .258 \\
\hline & Superior Occipital Gyrus & 19 & $L$ & -36.0 & -79.0 & 31.0 & -4.544 .866 \\
\hline \multirow[t]{2}{*}{132} & Medial Frontal Gyrus & $9 / 32$ & $L$ & -9.0 & 41.0 & 16.0 & -4.970 .238 \\
\hline & Medial Frontal Gyrus & 9 & $L$ & -9.0 & 41.0 & 28.0 & -4.356 .964 \\
\hline \multirow[t]{2}{*}{34} & Middle Frontal Gyrus & 10 & $L$ & -42.0 & 56.0 & 7.0 & -4.382 .877 \\
\hline & Middle Frontal Gyrus & 10 & $L$ & -33.0 & 47.0 & -2.0 & -3.886 .662 \\
\hline 38 & Cerebellum & * & $\mathrm{R}$ & 33.0 & -70.0 & -35.0 & -3.703 .044 \\
\hline
\end{tabular}


Table A5 | Brain regions showing positive connectivity with mPFC while reading negative stories > reading neutral stories.

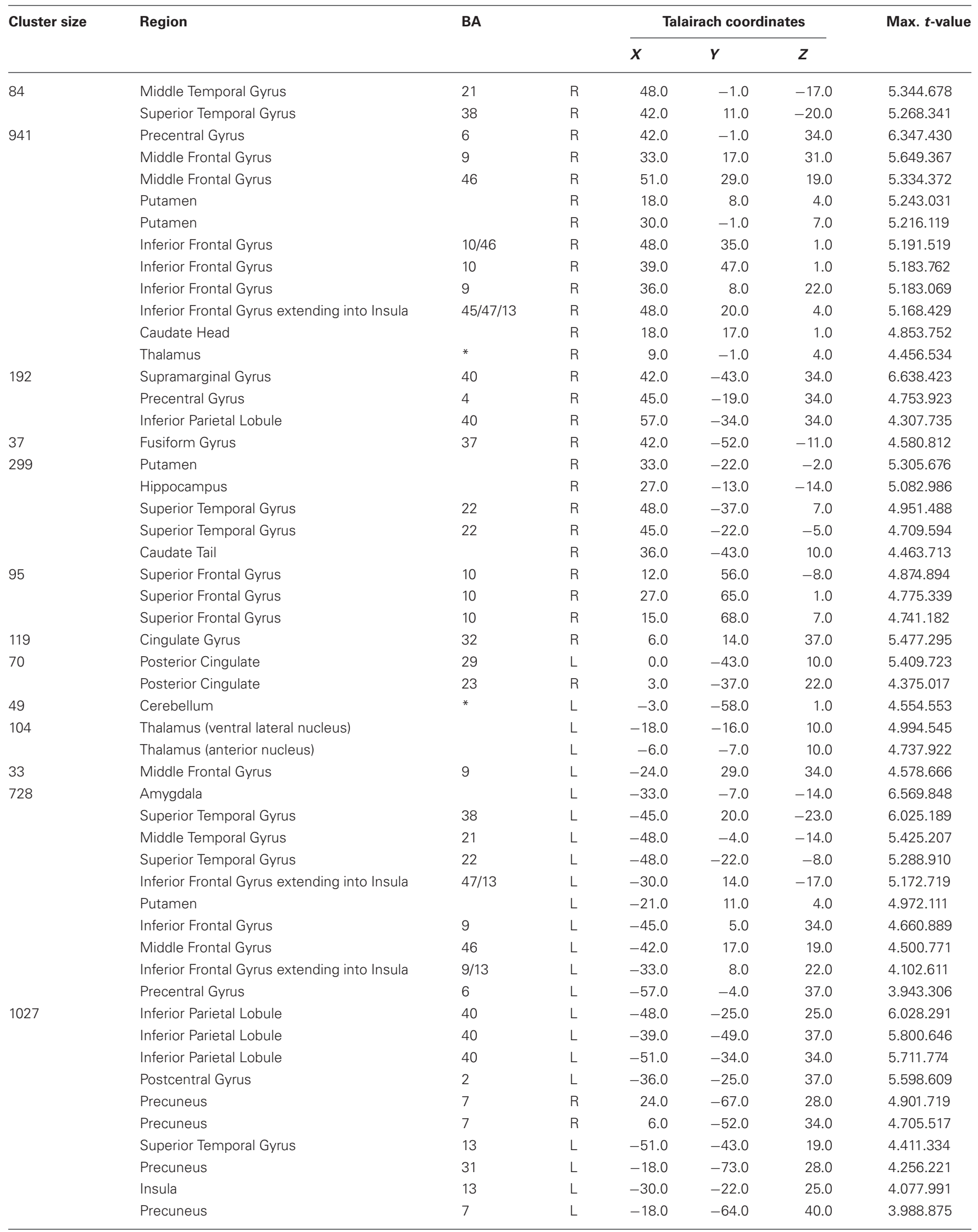


Table A6 | Brain regions showing positive connectivity with mPFC depending on individual tendency to put feel concern for other people (Positive correlation between the empathic concern scale and mPFC-connectivity while reading negative stories > reading neutral stories).

\begin{tabular}{|c|c|c|c|c|c|c|c|}
\hline \multirow[t]{2}{*}{ Cluster size } & \multirow[t]{2}{*}{ Region } & \multirow[t]{2}{*}{ BA } & & \multicolumn{3}{|c|}{ Talairach coordinates } & \multirow[t]{2}{*}{ Max. $t$-value } \\
\hline & & & & $X$ & $Y$ & $Z$ & \\
\hline \multirow[t]{2}{*}{81} & Inferior Frontal Gyrus/Anterior Insula & $47 / 13$ & $\mathrm{R}$ & 33 & 29 & 1 & 0.785256 \\
\hline & Putamen & & $\mathrm{R}$ & 24 & 8 & -5 & 0.655270 \\
\hline 17 & Posterior Cingulate & 31 & $\mathrm{R}$ & 18 & -58 & 19 & 0.719141 \\
\hline 16 & Middle Frontal Gyrus & 8 & $\mathrm{~L}$ & -33 & 17 & 43 & 0.830213 \\
\hline 53 & Insula & 13 & $\mathrm{~L}$ & -36 & 14 & -2 & 0.733469 \\
\hline
\end{tabular}

Table A7 | Prestudy results for valence and liking.

\begin{tabular}{|c|c|c|c|c|}
\hline \multirow[t]{2}{*}{ Conditions } & \multicolumn{2}{|c|}{$\begin{array}{c}\text { Valence } \\
(\text { Scale }-3 \text { to }+3)\end{array}$} & \multicolumn{2}{|c|}{$\begin{array}{c}\text { Liking } \\
\text { (Scale 1-7) }\end{array}$} \\
\hline & Mean & SD & Mean & SD \\
\hline Negative stories & -1.36 & 0.60 & 3.67 & 0.63 \\
\hline Neutral stories & 0.52 & 0.38 & 3.60 & 0.51 \\
\hline
\end{tabular}

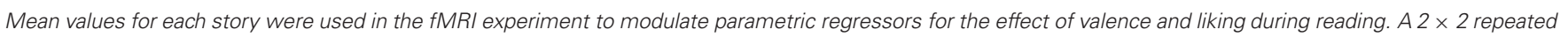
measures ANOVA was conducted with the factors story type (negative, neutral) and context (real, invented) to examine whether participant's judgments of valence reflect a clear differentiation between stories that have been categorized as neutral or negative in earlier studies during the stimulus selection phase. The main effect for story type $\left[F_{(1,31)}=72.83, p<0.001\right]$ showed that this is the case. Results revealed no main effect of context [F $\left.(1,31)<1, p<0.717\right]$ and no context $\times$

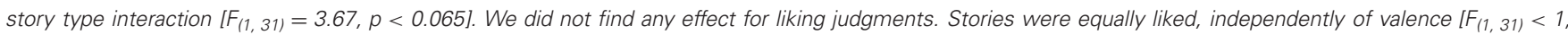
$p<0.741]$ or context labelling $\left[F_{(1,31)}=1.33, p<0.258\right]$.

Descriptive data on the item level show a clear difference on average valence for negative stories $(M=-1.36, S D=0.60)$ and neutral stories $(M=0.52, S D=0.38)$. Average liking values are very similar for negative $(M=3.67, S D=0.63)$ and neutral $(M=3.60, S D=0.51)$ texts. The latter finding fits nicely to the observation that an object must not provide positive valence in order to be liked. 